\title{
PERSPECTIVAS DOS ENFERMEIROS FRENTE ÀS PRÁTICAS EDUCATIVAS NO COTIDIANO DO TRABALHO
}

\section{NURSES' PERSPECTIVES REGARDING EDUCATIONAL PRACTICES IN DAILY WORK}

\section{PERSPECTIVAS DE LOS ENFERMEROS FRENTE A LAS PRÁCTICAS EDUCATIVAS EN EL COTIDIANO DEL TRABAJO}

\author{
Rosa Gomes dos Santos Ferreira ${ }^{1}$, Maria Manuela Vila Nova Cardoso ${ }^{2}$, Izabella de \\ Góes Anderson Maciel Tavares ${ }^{3}$, Ana Cristina Silva de Carvalho ${ }^{4}$, Alessandra Cabral \\ de Lacerda ${ }^{5}$
}

\begin{abstract}
RESUMO
Objetivo: Discutir a avaliação, sob a ótica dos enfermeiros, a respeito das práticas educativas no ambiente de trabalho, por meio das experiências vivenciadas por eles, enquanto participantes de programas de educação continuada e permanente. Método: Estudo qualitativo, realizado através de entrevistas abertas com treze enfermeiros de uma instituição universitária federal, do Rio de Janeiro, Brasil. Resultados: Demonstram que uma modalidade não pode ser vista como única possibilidade de educação em enfermagem, pois a educação sofre mudanças e ampliação conceitual, afiançando a ciência, como inesgotável, articulando-se à gestão e ao controle social, inserindo o profissional, na perspectiva das transformações organizacionais. Conclusão: A educação permanente traz subsídios à discussão do processo de trabalho sob a perspectiva da multidisciplinaridade, intersecção dos saberes e valorização do conteúdo e das vivências dos trabalhadores, no sentido da construção refinada de um produto assistencial. Descritores: Educação Continuada; Enfermagem; Aprendizagem.
\end{abstract}

\begin{abstract}
Objective: To discuss the evaluation, from the point of view of the nurses, regarding the educational practices in the work environment, through the experiences lived by them, as participants in continuing and permanent education programs. Method: Qualitative study, conducted through open interviews with thirteen nurses from a university institution, in Rio de Janeiro, Brazil. Results: The results demonstrate that a modality cannot be seen as the only
\end{abstract}

\footnotetext{
${ }^{1}$ Doutoranda em Enfermagem (EEAN-UFRJ), Mestre em Enfermagem pela Escola de Enfermagem Anna Nery (UFRJ). Coordenadora do Comitê de Ética em Pesquisa (IPUB-UFRJ). Coordenadora nacional da SIG telenfermagem em saúde mental (IPUB-UFRJ/RUTE/MS). Ouvidora do IPUB-UFRJ.

${ }^{2}$ Graduação em Enfermagem e Obstetrícia pela Escola de Enfermagem Anna Nery da UFRJ (1993), mestrado (1996) e doutorado (2007) em Enfermagem pela UFRJ. Professora Adjunto da Escola de Enfermagem Anna Nery, Departamento de Metodologia da Enfermagem.

${ }^{3}$ Enfermeira. $1^{\circ}$ Tenente do Quadro de Apoio à Saúde (Enfermeiro) da Marinha do Brasil.

${ }^{4}$ Mestre em Enfermagem pela Universidade Federal do Estado do Rio de Janeiro - UNIRIO - 2007. Doutoranda da Escola de Enfermagem Anna Nery (EEAN/ UFRJ). Docente da Universidade do Grande Rio UNIGRANRIO.

${ }^{5}$ Mestre em Enfermagem pela Universidade Federal do Estado do Rio de Janeiro (UNIRIO) -2007. Doutoranda da Escola de Enfermagem Anna Nery (EEAN/UFRJ). Docente da Universidade do Grande Rio (UNIGRANRIO).
} 
possibility of education in nursing, since education undergoes changes and expansion of its concept, valuing science as inexhaustible, articulating itself to the management and social control, inserting the professional, in the perspective of organizational changes. Conclusion: Continuing education brings subsidies to the discussion of the work process from the perspective of multidisciplinarity, intersection of knowledge and valuation of the content and the experiences of each worker, in the sense of the refined construction of a care product. Descriptors: Continuing Education; Nursing; Learning.

\section{RESUMEN}

Objetivo: Discutir la evaluación, bajo la óptica de los enfermeros, acerca de las prácticas educativas en el ambiente de trabajo, a través de las experiencias vivenciadas por ellos, como participantes de programas de educación continuada y permanente. Método: Estudio cualitativo, realizado por medio de entrevistas abiertas con trece enfermeros de una institución universitaria, de Río de Janeiro, Brasil. Resultados: Los resultados demuestran que una modalidad no puede ser vista como única posibilidad de educación en enfermería, pues la educación sufre cambios y ampliación de su concepto, valorizando la ciencia como inagotable, articulándose a la gestión y al control social, insertando al profesional en la perspectiva de cambios organizacionales. Conclusión: La educación permanente trae subsidios a la discusión del proceso de trabajo desde la perspectiva de la multidisciplinariedad, intersección de los saberes y valorización del contenido y de las vivencias de cada trabajador, en el sentido de la construcción refinada de un producto asistencial. Descriptores: Educación Continuada; Enfermería; Aprendizaje.

\section{INTRODUÇÃO}

Nenhuma prática educativa em saúde, particularmente em enfermagem, pode contemplar apenas aspectos e necessidades isoladas, seja de instituições, seja dos recursos humanos. ${ }^{1}$ Não somente as exigências gestoras e institucionais, devem subsidiar as práticas educativas de capacitação em enfermagem. A formação contínua dos profissionais deve ser capaz de proporcionar constante qualificação em saúde, propondo o desenvolvimento integral, enquanto sujeitos, trabalhadores e cidadãos. $^{2}$

Desta forma, no processo de aprendizado e capacitação, os elementos sugeridos pelas instituições e gestores, não podem desvincular-se do desejo e da demanda que o grupo apresenta e, para isto, se torna indispensável, ouvir seus anseios.

Para a American Nurses Association (ANA), a educação continuada e o desenvolvimento de pessoas se completam, sob a ótica da orientação e da educação em serviço, com a finalidade de desenvolver indivíduos, tanto como profissionais, tanto como pessoas, ponderando os objetivos e responsabilidades da organização. ${ }^{3}$

A educação permanente, modalidade mais contemporânea de prática educativa, atua sob o viés da transformação dos processos de saúde, 
participando do desenvolvimento das ações de ensino em serviço, ajuizando as singularidades e necessidades de formação e desenvolvimento para o trabalho, fortalecendo a linha da atenção integral à saúde. ${ }^{4}$

No entanto, ainda que a educação permanente considere a valorização do aprendizado através dos desafios inerentes ao processo de trabalho, este método, não se desvincula do retorno possível que um profissional crítico e consciente, têm a oferecer às instituições, quando participa de outros programas educacionais, tal como a educação continuada.

Ao contrário, o considera como produto indissociável da aplicação desta prática educativa no cotidiano do trabalho em saúde.

O programa de educação continuada pode ser avaliado como ferramenta capaz, a partir do momento em que considera o cenário e o dinamismo, presente no dueto "instituiçãotrabalhador" e suas necessidades de atender às expectativas acerca da reflexão para a qualificação dos processos cotidianos do trabalho.

Embora existam peculiaridades, há pontos comuns entre as modalidades educativas, especialmente no intrínseco à necessidade do desenvolvimento destas, baseadas no atendimento das necessidades e competências a serem atingidas, na aplicação das estratégias de ensinoaprendizagem e na conscientização e manutenção do interesse pelo aprendizado.

A educação continuada caracterizase pela continuidade das ações educativas e ainda que se fundamente em princípios metodológicos diferentes da educação permanente, quando implantada, possibilita a transformação profissional através do desenvolvimento de habilidades e competências e, assim, fortalece o processo de trabalho. ${ }^{5}$

A educação continuada surge a partir da década de 70 , no contexto da capacitação em enfermagem. Nesta época, as atividades educativas em saúde tinham como objetivo, contemplar as metas institucionais, através do trabalho

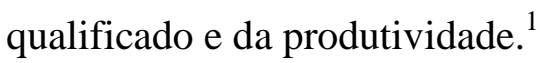

Em razão das lacunas advindas no referente ao atendimento das demandas de aprendizado dos grupos envolvidos no processo de ensino-aprendizagem, fez-se necessário vincular às práticas educativas, o panorama em que os trabalhadores se encontravam, bem como os produtos que deles emergiam e que para eles retornavam.

A prática pedagógica no trabalho da enfermagem no Brasil declara sua função ao acolher a globalização, tendo em vista a busca da aproximação deste mundo 
com as atividades de ensino-aprendizagem, para que estas sejam expressivas para os envolvidos no processo - educando e educador. ${ }^{3}$

Esta prática, em especial o método da educação continuada, merece atenção no que permeia o seu desenvolvimento, dada a necessidade de preparar indivíduos para o enfrentamento de modificações e desafios, conciliando as questões de desenvolvimento pessoal e coletivo com a organização e a sociedade. ${ }^{4}$

No conjunto dos deveres dos profissionais de enfermagem, o Código de Ética refere ser responsabilidade da classe, o aperfeiçoamento técnico, científico, ético e cultural, em benefício da pessoa, família e coletividade e do desenvolvimento da profissão. $^{6}$

Ao enfermeiro, é facultado o dever de manter-se, em ininterrupta aprendizagem, frequentando ações de programas de educação continuada, requerendo, procurando, promovendo e exigindo da instituição na qual trabalha apoio profissional na área específica de atuação. ${ }^{5}$

Às instituições hospitalares, é indispensável à implantação de atividades que proporcionem esta possibilidade aos profissionais com vistas a proporcionar um produto em saúde qualificado para a sociedade.
O Ministério da Saúde, por meio da Política Nacional de Educação Permanente em Saúde, sugere que os procedimentos de educação dos trabalhadores da saúde, se façam a partir da problematização, advertindo que as demandas por mudanças e melhorias, devam ser fundamentadas na análise do processo de trabalho, nas suas dificuldades e desafios. ${ }^{7-8}$

Mais importante que nomear, destacar especificidades e importância de uma modalidade em razão de outra, assinalar um objetivo comum às atividades ou as diferenças entre elas ou, ainda, discutir as implicações éticas e legais do processo de aprendizado e capacitação, está o produto final a ser aspirado na esfera dos objetivos dos gestores institucionais e das demandas dos trabalhadores e dos organizadores destas práticas, posto que a partir da interligação destes aspectos, surja um efetivo processo de ensinoaprendizagem.

Partindo do exposto, este estudo teve como objetivos conhecer e discutir a avaliação, sob a ótica dos enfermeiros, a respeito das práticas educativas no ambiente de trabalho de enfermagem, através das experiências vivenciadas em programas de educação continuada, permanente e em serviço.

Justifica-se ao se considerar o potencial estas atividades em capacitar, 
qualificar e garantir o contínuo aprendizado com vistas a excelência na prestação dos serviços de enfermagem.

\section{METODO}

Trata-se de um estudo de abordagem qualitativa e tipo descritivoexploratório que teve como cenário um instituto de assistência, ensino, pesquisa e extensão em saúde mental e psiquiatria do município do Rio de Janeiro, Brasil.

A população do estudo constituiuse de treze enfermeiros lotados nesta unidade e que atenderam aos critérios de inclusão, de possuir experiência anterior em programas de educação continuada e/ou permanente em enfermagem, nesta ou noutras instituições de saúde.

A coleta de dados ocorreu por meio de entrevistas não diretivas ou abertas voluntárias, registradas em gravador digital, sob a garantia de confidencialidade e anonimato.

$\mathrm{O}$ projeto foi encaminhado às instituições proponente e co-participante, obtendo status de aprovação, sob a ordem de pareceres consubstanciados números 209402 e 206034 (Plataforma Brasil / Comissão Nacional de Ética em Pesquisa CONEP), em atendimento aos pressupostos da Resolução 466 de 12 de dezembro de 2012 do CONEP.
Para o tratamento dos dados, adotamos a perspectiva da Hermenêutica de Profundidade, sustentada pelo sociólogo britânico John B. Thompson. Sua Teoria Social de Comunicação de Massa revela que os aspectos sócio-históricos, são fundamentais para a compreensão do que está em vigência na atualidade e é parte indissociável e mobilizadora dos constructos elaborados pelos grupos em sua historicidade. ${ }^{9}$

Por meio da aplicação do roteiro de entrevista aberta, dados relevantes a respeito do entendimento dos participantes no referente às modalidades educativas em saúde surgiram como conteúdo analítico.

Esta técnica de coleta implica em não dirigir ou arquitetar questões acerca do pesquisado e, sim, orientar e consentir ao entrevistado quanto à reflexão temática, expressando sua opinião e resgatando aspectos que avalie essenciais à lembrança e exploração de fatos. ${ }^{10}$

A relevância desta técnica incide em, através da possibilidade da livre expressão por parte do entrevistado, a ampliação dos achados e apresentação de um produto livre de direcionamentos por parte do entrevistador.

\section{RESULTADOS E DISCUSSÃO}

Como resultante da caracterização dos participantes, realizada através do 
emprego de um formulário de caracterização, evidenciamos que $28,5 \%$ destes, apresentavam experiências em programas de educação continuada, sob a condição de ouvintes e/ou coordenadores em recortes temporais diferentes e que, na mesma porcentagem $(28,5 \%)$, apenas sob a condição de ouvinte. Esta etapa correspondeu a uma primeira triagem, a qual encerrou os critérios de inclusão ao estudo central.

Entretanto, mediante a condução da entrevista aberta, evidenciamos que os depoentes nomeavam "educação continuada" qualquer experiência educativa no trabalho sem preocupar com conceituações, mesmo que as características do que relatassem na entrevista, ora convergissem para educação continuada, ora para educação permanente.

Desta forma, em primeira análise, destacamos que os participantes não assinalam, a primeiro tempo, as especificidades intrínsecas a cada programa, destacando o objetivo comum que permeia o processo educativo e não suas minúcias e nomenclaturas, conforme exposto nas falas a seguir.

Para assegurarmos o anonimato, indicamos os participantes do estudo, concedendo-lhes codinomes compostos pela letra "E", de Enfermeiro (a), e número da entrevista correspondente.
Existia um cronograma, uma agenda de assuntos a serem tratados conosco, a preocupação existia, com os participantes, não só com o hospital. Era educação continuada, penso eu. Sempre procurava comparecer. (E2)

Éramos convocados e havia uma lista de presença e assinávamos. Era obrigatório, pra atender ao diretor $e$ às chefias. Não nos perguntavam o que gostaríamos de assistir-Ia, pois era obrigatório e nossa avaliação ficava prejudicada, se faltássemos. (E4)

Achava muito interessante, pois partíamos de uma situação ocorrida e discutíamos em torno disto, como lidamos com isso, como aprender com isso. Não havia um nome específico para a atividade, mas era muito importante [...] Gostava de participar e contribuir. (E6)

Nestas falas, os depoentes assinalam suas experiências em atividades educativas desempenhadas em seus ambientes de trabalho. Algumas recebiam nomenclatura especifica e outras, desenvolviam-se não atreladas a tal preocupação.

O que nos cabe salientar é o fato de que, embora estas práticas aplicadas ao trabalho de enfermagem tivessem aspectos diferenciados, os participantes não apontavam estas distinções no intuito de tornar uma intervenção educativa de menor valor em relação à outra.

Destacaram o valor destas atividades dentro de cada cenário em que atuaram, enfatizando os objetivos e a importância destas vivências no contexto 
de ensino-aprendizagem e da formação contínua.

As atividades onde a preocupação ultrapassava o atendimento das metas gestoras, e envolvia a participação do grupo no referente às escolhas temáticas, a satisfação e a adesão tornavam-se maior, conforme se observa nos relatos abaixo:

Acredito que todas as ações sejam bemvindas, independente do nome que recebam. Isso não traz diferenças para os que participam. Nós temos resistência em participar, seja Educação Continuada, Permanente ou outra coisa parecida. Sempre temos um impeditivo, mas neste caso, vale a conquista do profissional. (E5)

Cada um dos programas recebe um nome, educação permanente, educação continuada... a meu ver, o que importa é a intenção, o objetivo comum. Isso é o que trará incentivo ao participante. (E7)

Participei de um Programa de Educação Permanente e em três hospitais, participei de Programas de Educação Continuada. Mesmo percebendo alguma diferença ou outra, o que vale é o convite e a liberdade em escolher o que se deseja discutir, mesmo sabendo que há uma meta institucional. Unir os objetivos atrai aquele que participa. (E2)

A partir da exposição acima, ressaltamos a importância das práticas educativas no cotidiano de enfermagem e não o apontamento de favoritismo de uma atividade em razão de outra.

Para os estudiosos das peculiaridades destas ações, há diferentes maneiras de conceituar educação em serviço, continuada e permanente, porém, todas têm intenções definidas que culminam no acolhimento das metas institucionais, desenvolvimento profissional e pessoal, ampliação de conhecimentos, refinamento de habilidades e promoção de mudanças de atitudes. ${ }^{11}$

Isto é corroborado por meio das falas dos entrevistados que, quando indagados a respeito do entendimento em relação ao que seria mais efetivo ou primordial ao desenvolvimento dos profissionais no âmbito do ensinoaprendizagem, apontaram por vezes, alguma especificidade entre as modalidades, mas destacaram prioritariamente o objetivo comum entre elas, que encerra a eficiência do processo de ensinar e aprender ininterruptamente no ambiente em que desenvolvem as atividades do trabalho.

[...] Não sou profissional especialista nesta área, mas participo destas atividades e não apreendo que uma modalidade tenha surgido para extinguir outra, porque seja melhor. Sempre entendi como uma atividade difícil de desenvolver, de despertar no profissional, o desejo e a reflexão acerca da importância de se participar. (E3)

Todas as modalidades devem existir, se complementar, se reformular, dentro dos locais $e$ para quem participa, mas não vejo uma melhor que a outra. (E1)

Para mim, não me importa saber se é educação continuada, treinamento ou aula, educação permanente... Importa-me o objetivo que 
é igual e para nosso grupo, além de ser um fruto de construção coletiva, entre as coordenações, instituições e demandas dos profissionais. (E8)

Para estes atores, a educação na enfermagem é um encontro de métodos, práticas, estratégias e espaços de ensino, sejam formais ou não, que interagem não se desmerecendo um ao outro e com um objetivo central que deve abalizar o processo.

Valorizam aspectos relacionais, democráticos (no que tange à escolha e demandas de conhecimento) e motivacionais, como fomento para $\mathrm{o}$ desenvolvimento das atividades educativas, independente de suas perspectivas particulares, onde o mais importante é o objetivo de ensinar e aprender que todas as modalidades têm em comum.

A educação para é um processo constante em busca de alternativas e soluções para os problemas de saúde vivenciados por pessoas e grupos em suas realidades, o que influenciará na reflexão e na transformação das práticas vigentes nos serviços, por meio da complementação e/ou aquisição de novos conhecimentos. Este fato não está atrelado, de acordo com as opiniões apresentadas, a quaisquer modelos educativos. ${ }^{12}$

Posto isto, constitui-se a premissa de que todo processo educativo não tem um fim, em si e, para tal, não se basta, sendo necessário retroalimentá-lo e reavaliá-lo pela dinâmica do trabalho de enfermagem, onde a Educação Permanente e Continuada são ferramentas para essa construção. $^{13}$

A Educação Continuada em Enfermagem é um processo que busca proporcionar ao indivíduo a obtenção de conhecimentos para que ele atinja sua capacidade profissional e desenvolvimento pessoal, considerando a realidade social e da instituição. ${ }^{14,15}$

A Educação Permanente trabalhava sob a perspectiva da transformação, participa do desenvolvimento das ações de ensino em serviço e consideram as singularidades, necessidades de formação e desenvolvimento para o trabalho em saúde, fortalecendo a atenção integral a saúde. ${ }^{15-17}$

Embora esta modalidade se apresente no cenário atual, sobretudo na América Latina e no Brasil, como padrão que procura acolher as políticas públicas de saúde, considerável grupo de trabalhadores de enfermagem são participantes e valorizam a educação continuada como ferramenta imprescindível ao crescimento humano e profissional, enfatizando sua relevância e necessidade de aplicação dentro dos contextos assistenciais. 


\section{CONCLUSÃO}

Ao finalizarmos este estudo, o qual certamente provocará novas discussões, asseguramos que as práticas educativas (educação em serviço, educação continuada ou educação permanente) advêm do contexto sócio-histórico e político apresentado em determinadas ocasiões, que conduziu todo o processo que amparou o surgimento, desenvolvimento e implantação de cada modalidade educativa, a fim de atender os objetivos inerentes às demandas, seja dos grupos, seja das instituições, seja das coordenações setoriais.

Entretanto, estes não são os motivos suficientes a fadar instituições a adotar uma única intervenção educativa, sendo por vezes, a intersecção das modalidades, algo valioso dentro dos cenários de trabalho.

Cabe evidenciar que a diversidade de práticas educativas ofertadas no cotidiano de trabalho de Enfermagem, ao passo que traz diversidade, confere entrave e é uma limitação de adesão, por parte da instituição e dos grupos, pois cada uma das modalidades requer dispositivos e adequações diversas, no intuito de surtirem êxito.

Os trabalhadores entrevistados ressaltam que o mais importante neste contexto, está na aplicabilidade, objetivos e participação destes, na escolha dos assuntos abordados nas capacitações. Se tais aspectos não forem considerados, uma modalidade educativa não será melhor em razão de outra.

Os gestores das instituições e organizadores destes programas educativos devem compreender que o acolhimento das questões de conhecimento devem ser atendidas, sob óticas de ensinoaprendizagem que se entremeiam e não que competem entre si.

Em se tratando de educação cotidiana em enfermagem, uma modalidade não pode ser adotada como a única possibilidade, posto que as educações continuadas, bem como os demais programas, passam por modificações e alargamento do seu conceito.

Associando-se a edificação do conhecimento, a partir da subjetividade dos trabalhadores, apreciando a ciência como fonte inesgotável, articulando-se à gestão e ao controle social, colocando-se na perspectiva de transformações organizacionais em que o profissional está inserido e atendendo ao que é preconizado 
pelo campo da formação de pessoas, procura-se atingir um objetivo comum, que se refere à capacitação.

As necessidades de integração entre estas práticas não estão exclusivamente no âmbito das pessoas, mas na seara das designações e posições que organizadores destes programas adotam ao defenderem seus "ideais".

O que deve predominar são os objetivos, anseios e disponibilidade em aprender dentro do árduo cotidiano de trabalho de enfermagem, trazendo aplicabilidade e êxito às implantações.

A diferença de concepções, não podem jamais dirigir discussões e disputas institucionais e, sim, nortear os processos educativos sob o viés da democracia, paridade, reflexão e qualificação das pessoas, das instituições e do processo de trabalho.

Por fim, apontamos como limitação deste estudo, o fato de, ainda, por parte dos gestores de serviços, se fazer compreender, a necessidade de conceder voz ao colaborador, no que tange as suas demandas de aprendizado, para que a adesão aos programas educativos sejam de fato, eficientes, e não meramente, em atendimento produto profissional.

Porém, oportunidades científicas de publicização de materiais desta monta, fortalecem resultados de investigações científicas e fomentam discussões acadêmicas e de repercussões práticas significativas.

\section{REFERÊNCIAS}

1- Nunez RS, Luckesi MAV. Educação em serviço: fator de desenvolvimento de recursos humanos em enfermagem. Rev Bras Enferm. 1980; 33(1):54-80.

2- Da Silva LAA, Schubert Backes VM, Lenise Prado M. La educación em el trabajo de enfermeria em el contexto latinoamericano. Enferm Glob. 2014; 13(34):346-58.

3- Marinopoulos SS, Dorman T, Ratanawongsa N, Wilson LM, Ashar BH, Magaziner JL, et al. Effectiveness of continuing medical education. Evid Rep Technol Assess. [Internet]. 2007 [citado em 20 set 2017]; 149:1-69 Disponível em: https://archive.ahrq.gov/downloads/ pub/evidence/pdf/cme/cme.pdf

4- Faria JIL, Casagrande LDR. A educação para o século XXI... e a formação do professor reflexivo na enfermagem. Rev Latinoam Enferm. 2004; 2(5):821-7.

5- Montanha D, Peduzzi M. Educação permanente em enfermagem: levantamento de necessidades e resultados esperados segundo a concepção dos trabalhadores. Rev Esc Enferm USP. 2010; 44(3):597604.

6- Conselho Federal de Enfermagem (Brasil). Resolução no 311 de 08 de fevereiro de 2007. Aprova a reformulação do Código de Ética dos Profissionais de Enfermagem. Brasília, DF: COFEN; 2007.

7- Castilho V. Educação continuada em enfermagem: a pesquisa como possibilidade de desenvolvimento 
de pessoal. Mundo Saúde. set-out 2000; 24(5):357-60.

8- Girade MG, Cruz EMNT, Stefanelli MC. Educação continuada em enfermagem psiquiátrica: reflexão sobre conceitos. Rev Esc Enferm USP. 2006; 40(1):105-10.

9- Thompson JB. Ideologia e cultura moderna. Rio de Janeiro: Vozes; 2011.

10-Richardson RJ. Pesquisa social: métodos e técnicas. 3ed. São Paulo: Atlas; 2010.

11-Ministério da Saúde (Brasil), Conselho Nacional de Saúde. Política nacional de educação permanente para o controle social no Sistema Único de Saúde - SUS. Brasília, DF: Ministério da Saúde; 2006.

12-Farah BF. Educação em serviço, educação continuada, educação permanente em saúde: sinônimos ou diferentes concepções? Rev APS. 2003; 6(2):123-25.

13-Montanha D, Peduzzi M. Educação permanente em enfermagem: levantamento de necessidades e resultados esperados segundo a concepção dos trabalhadores. Rev Esc Enferm USP. 2010; 44(3):597604.

14- Cotrim-Guimarães IMA. Programa de educação permanente e continuada da equipe de enfermagem da clínica médica do Hospital Universitário Clemente de Faria: análise e proposições. [dissertação]. Rio de Janeiro: Escola Nacional de Saúde Pública Sergio Arouca; 2009.

15-Ceccim RB. Educação permanente em saúde: desafio ambicioso e necessário. Interface Comum Saúde Educ. 2005; 9(16):161-8.

16-Bezerra AL. O contexto da educação continuada em enfermagem. São Paulo: Lemar e Martinari; 2003.
17-Peixoto LS, Gonçalves LC, Costa TD, Melo CMT, Cavalcanti ACD, Cortez EA. Educação permanente, continuada e em serviço: desvendando seus conceitos. Rev. Enferm. Global. 2013; 12(29):324340.

RECEBIDO: $27 / 12 / 2017$

APROVADO: 08/10/2018

PUBLICADO: $12 / 2018$ 